\title{
Effects of Stress Management Training by Using Cognitive-Behavioral Method on Reducing Anxiety and Depression among Parents of Children with Mental Retardation
}

\author{
Abbas Ali Hosseinkhanzadeh ${ }^{1}$, Taiebeh Yeganeh ${ }^{2}$, Nouradin Rashidi ${ }^{3}$, \\ Ghasem Zareimanesh ${ }^{3}$, Nouradin Fayeghi ${ }^{4}$ \\ ${ }^{1}$ University of Guilan, Rasht, Iran \\ ${ }^{2}$ Young Researchers Club, Tonekabon Branch, Islamic Azad University, Tonekabon, Iran \\ ${ }^{3}$ M.A. in Counseling, Kermanshah, Iran \\ ${ }^{4}$ M.A. in Psychology, Kermanshah, Iran \\ Email: Khanzadeh@ut.ac.ir
}

Received September $28^{\text {th }}, 2012$; revised November $3^{\text {rd }}, 2012$; accepted November $18^{\text {th }}, 2012$

\begin{abstract}
Present study is designed to investigate the effects of stress management training by using cognitive behavioral method on anxiety and depression among parents of children with mental retardation. This study is a quasi-experiment that designed as pretest and post-test with control group. The statistical population of study included all parents with mental retarded children from city of Babol in 2011-2012. Sample population was including 40 parents that were selected cluster sampling and allocated in experimental and control groups (20 parents for experimental group and 20 for control group). The experimental group trained during 10 sessions of stress management with method of cognitive-behavioral, whereas during this period the control group did not received any intervention. Both groups in pre-test and post-test assessed by using anxiety and depression scale and results were analyzed by using independent t-test. The results of t-test showed that there were no significant differences between two groups in pre-test, but stress management training with method of cognitive-behavioral in experimental group were significantly reduced scores of anxiety and depression. The results of this study showed that stress management by using cognitive-behavioral method decreases depression and anxiety scores compared with the control group. Due to psychological problems of parents with mental retarded children, cognitive-behavioral stress management training program can be used as intervention method to reduce anxiety and depression in order to decrease vulnerability.
\end{abstract}

Keywords: Stress Management; Cognitive-Behavioral Method; Anxiety; Depression

\section{Introduction}

During the last two decades movements of institutions has been changed focusing of primary care from psychiatry hospitals into community mental health centers, and because of budget, resources and facility limitations, families of patients had to take responsibilities such as being practical assistance or emotional supports (Gutierrez-Maldonado et al., 2005). In the past, children who were in institutions, but now they are living in family environment which is better for their development but on the other hand these changes have great pressures on families (Pelchat \& Lefebvre, 2004). Generally interesting to the issue of psychological needs of caregivers goes back to 1950 (Honea et al., 2008). Some experts underline that role of caregivers often accompanied by set of rewards and positive reinforcement (Picot, 1996).

The birth of a child with a disability affects the dynamic and interaction among family members which could leads to crisis within family. Specially issue of mental retardation in children is very serious because family with mental retarded children have problems in parental system, marital relationships, sibling relationships, even it affects their external system such as friend, family, neighbors, school and will cause more pressure within the system, at this point emotional state and physiological thoughts become abnormal then leads to vulnerability in cognitive activities which outcome of these behavioral problems will bring out depression and anxiety (Hernandez, 2005). Regarding to this issue, Goffman (1963) believes that experiences of stigma not only affect people who carrying stigmatized traits, but also will expand to those have directly relationship with people who carry negative attributions. Affiliates could internalize their stigma and affect their life, so they might face with contagious stigma which is complex phenomenon (Gray, 1993; Green, 2003).

The birth of a child with mental retardation could lead to deep impact on families, thus parents of children with special needs are facing more problems than parents of normal children which affect their psychological well-being (Rohini, 2012). This kind of birth is one of the most stressful events among individual's life (Mc Conkey et al., 2008). Some factors such as advances in medicine and technology, effect mental retarded children to live longer and healthier (Saloviita, Itallina, \& Lei- 
nonen, 2003). The continuing care of children with mental retardation is often stressful for parents (Esdaile \& Greenwood, 2003). The effects on family unit can be economic, social, and emotional in nature. Researchers have indicated that parents of children with mental retardation are generally at risk for a variety of emotional difficulties (Beckman, 1991; Khamis, 2007). The cumulative impact of daily hassles and difficulties in dealing with disabled children represent significant stressors that may subsequently affect parents and family functioning. In particular, a great deal of evidence points to associations between the severity and frequency of behavior problems of children with intellectual disabilities and parental stress and psychiatric problems such as depression and anxiety (Baker, Blacher, Crnic, \& Edelbrock, 2002).

Severe and long term stresses can affect adaptation ability, and reduce pleasure which results with depression (KiecoltGlaser, 2002). According to the studies, adapting to mental retarded children has some stages, in the first stage family encounters with crisis such as anger and denial. Then family will experience emotional turmoil, anger, guilt, depression and shame that can reduce their self esteem, at this point child will be under excessive care or ostracized by family and finally child will be accepted by family (Heyward, 2000).

Varies studies have confirmed that parents of mentally retarded children showed higher levels of stress than children with normal status. The results of Shieve and colleagues research in 2007 showed that the presence of stresses among parents of children with special needs are $44 \%$ which this amount among parents with normal children are $11 \%$. Also research of Cushner-Weinstein and colleagues in 2008 have been reported amount of stresses among parents with epilepsy children is around $45 \%$.

The most important problems of these parents are: 1) Difficulty in accepting mental retarded children; 2) Fatigue of caregiver; 3) Issued that related to leisure time; 4) Financial problems of family; 5) Medical things (Khamis, 2007). All those cases make stresses on families, especially on mothers, because mothers are spending more time to care their children due to the traditional role of "care", also they are more under risk of depression compared with men (McConkey et al., 2007; Pinquart \& Sorensen, 2006). Also they might abandoned by their spouse for reasons such as lack of willingness to accept additional responsibilities or stigma (Rohini, 2012).

Some features such as the nature of disabilities, behavioral problems of children, emotional status, lack of social support, presence of additional disabilities in children, stressful resources associated with the inability of children can lead to increasing anxiety even depression among parents (Kaplan, 2010; Zaidman-Zait, 2007), that in turn, existence of these psychological abnormalities significantly contribute to reducing quality of life (Sakakura et al., 2007).

One of the variables that directly correlated with parental stress is severity of disability. Children who are born with severe injuries are more likely to make the family anxious because their family has more responsibility toward their children (Dabrowska \& Pisula, 2010). According to the extent of the severity, their needs will increase so then they need more services from their family. Additional role is imposed on parents in the birth of children with disabilities especially on mothers make lots of stress. In addition mothers also have responsibility such as educating their children (Parrette \& Brotherson, 1996).

Parette \& Brotherson discuss reasons that underline need of providing educational services to parents. From their view point parents with mental retardation experience high level of anxiety and stress thus this requires specialized and training to identify them. These children often need special cares because of delaying or failure to obtain customs such as toilet training, dressing, eating, clothing, and problems such as bed-wetting and seizures. In order to achieve diagnosis and treatment, parents become strict and this might result with financial loss, energy and time in order to take care of themselves or other members of family.

The subject of stress management by using cognitive-behavioral method tends to be very important issue now a day, because it particularly affects function of family and relationship within the family members which might results to caught vicious cycle. Family experiences anxiety and then causes various psychological problems among members of family, thus this gradually will lead to negative effect on family function. A child that develops in dysfunctional family that faces with many conflicts is more likely to have emotional, behaveioral and educational problems. These problems have a negative impact on family members and this cycle continues and becomes more complex every day. For breaking this cycle stress management training by using cognitive-behavioral method is important because this method focuses on cognitive-behavioral approach.

Stress management increases the ability of individual in order to coping with stressful situation to reduce the level of stress. This method of intervention consist of elements such as raising awareness about stress, relaxation training, identifying inefficient thoughts, cognitive restructuring, problem solving, anger management, self management and planning activities (Linden, 2005; Anderson, 2006; Antoni et al., 2009). Such interventions are necessary because the level of psychological well-being of parents directly associated with positive and effective interaction between them (Ruhuny, 2012). Considering the fact that there exists a significant hiatus in the examination of parental stress and psychological distress among parents of children with mental retardation in Iran, present study investigates whether stress management training by using cognitivebehavioral method reduces the anxiety and depression among parents of children with mental retardation or not?

\section{Method}

\section{The Sample and Sampling}

Present study is quasi-experiment designed as pre-test and post-test with control group. Samples consist of all parents with mental retarded children from city of Babul in 2011-2012. Sample population was including 40 parents that were selected by cluster sampling and allocated randomly in experimental and control groups (20 parents for experimental group and 20 for control group).

\section{Research Tools}

In this study to gather data from pre-test and post-test, scale of anxiety and depression of SCL-90-R questionnaire is used. This scale in addition to psychiatric patients, are useful and appropriate in the case of alcohol and drug addicts, patients with cancers, patients with heart failure and those who are under stressful situation. This scale chosen from authors, because it has short, simple and brief buoy of anxiety and depression, also with respecting to the low educated patients was the best scale 
in comparing with other scales in order to measure depression and anxiety. It is based on Likert scale of five choices (Not at all, Little, Partly, High, Very high) and scored as (0, 1, 2, 3, 4). In an Iranian study on depression and anxiety, coefficient validate scale is reported as $92 \%$ and $86 \%$ (Khorramabady et al., 2009). In the study of Riahi and colleagues (2010) reliability coefficient was calculated for the scale of mental health based on its reliability is equal with 0.932 which shows extreme harmony between the items of this scale.

\section{Introducing the Intervention Program}

After running the pre-test on the both groups, experimental group attended in stress management program by using cognitive-behavioral method and after intervention, test scores were collected. Program of stress management by using cognitivebehavioral method (Antoni, Ironson, \& Schneiderman, 2007) includes 10 session of 90 minutes in experimental groups was performed as follows: In general, each session consists of two parts, first steps contains techniques of stress management and second part includes relaxation exercises.

First Session: Describe the factors of causing stress, response to factors of causing stress, awareness of the physical effects of stress and its possible consequences on health-muscle relaxation for 16 groups of muscles.

Second Session: Stress and awareness (of automatic thoughts and physical sensations) — muscles relaxation for 8 muscles.

Third Session: Describe the relationship between thoughts and emotions-diaphragmatic breathing, muscle relaxation for 4 groups of muscles.

Fourth Session: Identification of negative thinking and cognitive distortions-breathing, illustration and passive muscle relaxation.

Fifth Session: Replacement of logical thoughts-Self-training for being heaviness and heat.

Sixth Session: Learn to deal effectively-Self-training for heart rate, respiration, abdomen and forehead.

Seventh Session: Implementation of effective coping response-Self-training with illustration and self-induction.

Eighth Session: Anger management training and mantra meditation.

Ninth Session: Gary expresses training - Counting breath meditation.

Tenth Session: Social Support-Overview of program and personal stress management program.

The presentation of material in each session was first to review the material of last meeting, then materials of that session were presented, and at the end of that session the new materials were reviewed and finally new task has been given to them. After completing program, post-test were administrated to both groups in order to determine degree of anxiety and depression.

\section{Results}

In order to determine the effect of cognitive behavioral stress management training in the both experimental and control groups, first scores on the variable of depression and anxiety in the pre-test and post-test was calculated. Table 1 shows profile of the sample.

In order to compare experimental and control groups in terms of effectiveness of stress management training on anxiety and
Table 1.

Means and standard deviation of experimental and control groups.

\begin{tabular}{cccc}
\hline & $\mathrm{N}$ & MEAN & SD \\
\hline Experimental & 20 & 41.07 & 4.35 \\
Control & 20 & 40.67 & 5.8 \\
\hline
\end{tabular}

depression, the independent t-test was used where the total average difference between pre-test scores - post-test (d score) has been compared in two groups (One of the common statistical methods in the design of pre-test and post-test is with control group). The results are shown in Tables 2 and 3.

According to Table 2, there is no significant difference in average of two groups of control and experimental, but after stress management training and in comparison of averages in post-test, test, results of t-test indicated that there are significant differences between two groups in terms of anxiety variable. Final amount of $t$ is outcome of immunization effect on anxiety $-4 / 1$ which is on $P \leq 0.001$ and is meaningful with $1 \%$ alpha, in other words we can say that the effect of immunization training in reducing anxiety is significant.

The data in Table 3 also shows that there is no significant difference between two groups in pre-test in terms of depresssion variable, but after stress management training, results of independent $\mathrm{t}$-test indicates that there are significant differences between two groups in terms of depression variables. The final amount t outcome of immunization effect on depression is $-3 / 4$ which is on $P \leq 0.001$ and is meaningful with $1 \%$ alpha. In other words stress management training, significantly reduced depression. Overall, there are significant differences between scores of pre-test and post-test in control and experimental groups on anxiety and depression. These findings indicate that cognitive-behavioral stress management training is effective and reduces anxiety and depression in parents of children with mental retardation.

\section{Discussion and Conclusion}

Pressure of psychiatric care that is imposed on caregiver reduces the quality of care and can jeopardize their mental and physical health and releasing these tensions and pressures without treatment and intention can lead to reducing physical and mental health of home caregivers as hidden patient (Goode et al., 1998). Therefore, some strategies to reduce stress for the parents seems to be necessary, such as family counseling, coping skills training, inadequate social support and providing professional classes for the parents. Providing such interventions defined as mental health professionals to reduce tensions from home caregivers (Riebscheger et al., 2008; Gutierrez-maldonado \& Caqueo-Urizar, 2007).

Therefore, this study examines the impact of cognitive-behavioral stress management training in reducing anxiety and depression among parents of children with mental retardation. The results of this study has been proved that cognitive-behavioral stress management training reduce depression and anxiety scores in experimental group comparing with control group, findings of this result are consistent with the results of the research study Baron (1994), Keogh et al. (2005), Vivian Khamis (2006), Sheehy \& Horan (2004), Rohini (2012). Findings of these researchers also indicated that stress management by using cognitive-behavioral method help people to deal with 


\section{A. A. HOSSEINKHANZADEH ET AL}

Table 2.

Results of independent t-test in order to compare experimental and control groups on anxiety.

\begin{tabular}{ccccccc}
\hline & & $\mathrm{N}$ & Mean & $\mathrm{SD}$ & $\mathrm{T}$ & $\mathrm{SIG}$ \\
\hline \multirow{3}{*}{ Pre-test } & Experiment & 20 & 18.8 & 1.86 & 0.35 & 0.73 \\
& Control & 20 & 18.6 & 1.18 & & \\
\multirow{3}{*}{ Post-test } & Experiment & 20 & 16.13 & 1.4 & & \\
& Control & 20 & 18 & 1.25 & -3.84 & 0.001 \\
\multirow{3}{*}{ Test score difference } & Experiment & 20 & -2.66 & 1.34 & & \\
& Control & 20 & -0.6 & 1.35 & -4.1 & 0.001 \\
\hline
\end{tabular}

Note: $\mathrm{DF}=38$.

Table 3.

Results of independent t-test in order to compare scores between control and experimental groups on depression.

\begin{tabular}{ccccccc}
\hline & & $\mathrm{N}$ & MEAN & SD & T & SIG \\
\hline \multirow{2}{*}{ Pre-test } & Experiment & 20 & 28.53 & 3.25 & 0.69 & 0.49 \\
& Control & 20 & 27.73 & 3.01 & & \\
Post-test & Experiment & 20 & 24.4 & 3.2 & -2.7 & 0.012 \\
& Control & 20 & 27.4 & 2.85 & & \\
Test score difference & Experiment & 20 & -2.66 & 1.34 & -0.4 & 0.002 \\
\hline
\end{tabular}

Note: $\mathrm{DF}=38$

particular pressures in order to improve quality of their life.

Husting \& Beck (2004) investigated group intervention program with the aim of reducing anxiety among parents of children with mental retardation. They believe that parents of children with mental retardation are increasingly vulnerable to stress and other psychological problems such as depression and anxiety thus, they need to interceptive programs in order to decrease stress. Review of Husting \& Beck has shown that among intervention programs, the cognitive-behavioral method have the greatest effective impact in reducing stress. The above findings can be explained by cognitive-behavioral strategies. By using cognitive stress management training try to identified unreasonable thoughts, inefficient, and factors that arousing anxiety and depression and try to help them to have insight in order to replace rational thoughts. This will enhance their selfesteem and psychological adequacy thus will lead them to achieve more resources to help their disabled child. As Lazarus \& Folkman (1984) argue that when individual coping with stress, if resources are available to help, will show less vulnerability to stress.

The nature of this type training has been effective in reducing the stress of people, because the parents all were well trained group. Berg \& colleagues (1998) underline nature of all problems based on social and interpersonal. Participation in those kinds of trainings give them chance to share their problems, understand problems of others, learn new ways to solve problems and learn constructive plans in order to cope with stress. Actually, this is kind of social support, emotional and informational support (Thoits, 1986). Social support affect life satisfaction in two ways: first way is direct effect or general effect of social support on life satisfaction without considering the level of distress experienced by individual, it effects the life satisfaction, and second way consists of indirect effect or mediator effect that protect people in facing with stressful conditions (Van Leeuwen et al., 2010).

In order to provide another explanation, Lazarus and Folkman (1984) underline that major issue is how individual perceive or deal with stress that might affect outcome, thus if people find more ways to compromise to cope with environmental stressors and reduce level of stress.

In the present study aim was to teaching various ways in order to challenge with negative thoughts and attitudes associated with having a mental retarded child, and to reduce symptoms of anxiety and depression and as a result improve and resolve impaired functions of activities, life satisfaction, self-esteem and social relationships. Prevalence of anxiety and depression among parents of children with mental retardation is in high level, thus therapies such as cognitive-behavioral therapy beside other methods seems to be necessary, because those treatments can teach parents to learn how deal with their children in order to adapt their social situation. Thereby, improving compliance, while reducing the harmful effects of these disabilities will help to children and parents in order to comply with the disease and also will help them find the best solutions (Williams et al., 2003). In sum, increasing the mental health leads to physical health and finally to healthy society. The final point that must be pay attention is that importance of continuing to improve the level of psychiatric services for these individuals and their families (Awad \& Voruqanti, 2008). So, in further studies suggested that to use other methods of therapy and compare them with each other which have been proven that are effective in reducing anxiety and depression for parents. 


\section{REFERENCES}

Anderson, K. L. (2006). Negative mood and quality of life in parents with mental retardation children. Quality Life Research, 15, 49-54.

Antoni, M., Ironson, G., \& Schneiderman, N. (2009). Cognitive-behavioral stress management. Jahade Daneshgahi, 2, 33-230.

Awad, A. G., \& Voruqanti, L. N. (2008). The burden of schizophrenia of caregivers: A review. Pharmacoeconomics, 26, 149-162. doi:10.2165/00019053-200826020-00005

Baker, B. L., Blacher, J., Crnic, K., \& Eddelbrock, C. (2002). Behavior problems and parenting stress in families of three-year-old children with and without developmental delays. American Journal on Mental Retardation, 107, 433-444. doi:10.1352/0895-8017(2002)107<0433:BPAPSI $>2.0 . C O ; 2$

Baron, H. (1994). Advances in the psychological treatment of anxiety disorders: Implications for national health care. Archives of General Psychology, 53, 727-735.

Beckman, P. J. (1991). Comparison of mothers and fathers perceptions of the effect of young children with and without disabilities. American Journal on Mental Retardation, 95, 585-595.

Berg, R. C. Landreht, G. L., \& Fall, K. A. (1998). Group counseling: Concepts and procedures. Philadelphia, PA: George H. Buchanan Company.

Cushner-Weinstein, S., Dassoulas, J. A., Sarah, E. S., Henderson, P. L., Pearl, W. D. G., \& Weinstein, S. L. (2008). Parenting stress and childhood epilepsy: The impact of depression, learning and seizure related factors. Epilepsy \& Behavior, 13, 109-114. doi:10.1016/j.yebeh.2008.03.010

Dabrowska, A, \& Pisula, E. (2010). Parenting stress and coping styles in mothers and fathers of preschool children with down syndrome. Journal of Intellectual Disabilities Research, 54, 266-279. doi:10.1111/j.1365-2788.2010.01258.x

Esdaile, S. A., \& Greenwood, K. (2003). A comparison of mother's and father's experience of parenting stress and attributions for parentchild interaction outcome. Occupational Therapy International, 10, 112-115. doi:10.1002/oti.180

Goffman, E. (1963). Stigma: Notes on the management of spoiled identity. New York: Prentice-Hall.

Goode, K. T., Haley, W. E., Roth, D. L., \& Fotd, G. R. (1998). Predicting longitudinal changes in caregiver physical and mental health: A stress process model. Health Psychology, 17, 190-198.

Gray, D. (1993). Perceptions of stigma: The parental of autistic children. Sociology of Health and Illness, 15, 102-120.

Green, S. E. (2003). What do you mean what's wrong with her: Stigma and lives of families of children with disability. Social Science \& Medicine, 57, 1361-1374.

Gutierrez-Maldonado, J., \& Caqueo-Urizar, A. (2007). Effectiveness of a psycho-educational intervention for reducing burden in Latin American families of patients with schizophrenia. Quality Life Research, 16, 739-747.

Gutierrez-Maldonado, J., Caqueo-Urizar, A., \& Kavanagh, D. (2005). Burden of care and general health in families of patients with schizophrenia. Social Psychiatry and Psychiatry Epidemiology, 40, 899904.

Hastings, R. P., \& Beck, A. (2004). Practitioner review: Stress intervention for parents of children with intellectual disabilities. Journal of Child Psychology and Psychiatry, 45, 1338-1349.

Hernandez, N. (2005). Stress management program for parents of children diagnosed with attention deficit hyperactivity disorder. Dissertation abstract. FL: Carlos Abizo University.

Heyward, W. L. (2000). Exceptional children. Upper Saddle River, NJ: Prentice Hall Inc.

Honea, N. J., Brintnall, R. A., Given, B., Sherwood, P., Colao, D. B., Somers, S. C., \& Northouse, L. L. (2008). Putting evidence into practice: Nursing assessment and interventions to reduce family caregiver strain and burden. Clinical Journal Oncology Nursing, 12, 507-516.

Kaplan, R. L. (2010). Care giving mothers of children with impairments: Coping and support in Russia. Disability \& Society, 25, 715721.

Keogh, E., \& Bond, F. W., \& Flaxman, P. E. (2005). Improving acade- mic performance and mental health through a stress management intervention: Outcomes and mediators of change. Behavior Research and Therapy, 44, 339-357.

Khamis, V. (2006). Psychological distress among parents of children with mental retardation in the United Arab Emirates. Al-Ain: United Arab Emirates University.

Khamis, V. (2007). Psychological distress among parents of children with mental retardation in the United Arab Emirates. Social Science \& Medicine, 64, 850-857.

Khorramabady, R., Poretemad, H. R., Thahmasyan, K., Chimeh, N. (2009). Parenting stress in mothers of children with Autism disorders with normal children. Journal of Family Research, 19, 387-399.

Kiecolt-Glaser, G. K. (2002). Stressful life events and depressive symptoms: Differences based on history of prior depression. British of Psychiatry, 176, 373-378.

Lazarus, R., \& Folkman, S. (1984). Stress, appraisal, and coping. New York: Free Press.

Linden, W. (2005). Stress management: From basic science to better practice. New York: Sage Publication.

McConkey, R., Kennedy, M. T., Chang, Y. M., Jarrah, S., \& Shukri, R. (2008). The impact on mothers of bringing up a child with intellectual disabilities: Across-cultural study. International Journal of Nursing Study, 45, 65-74.

Parette, H. P., \& Brotherson, M. J. (1996). Family participation in assistive technology assessment for young children with mental retardation and developmental disabilities. Education and Training Mental Retardation and Developmental Disabilities, 37, 29-36.

Pelchat, D., \& Lefebvre, H. (2004). A holistic intervention program for families with a child with a disability. Journal of Advanced Nursing, 48, 124-131.

Picot, S. J. (1996). Family caregivers: Windows into their worlds. Reflections, 22, 13-14.

Pinquart, M., \& Sorensen, S. (2006). Gender differences in caregiver experiences: An update meta-analysis. Journal of Gerontology: Psychological Sciences, 61, 33-45.

Riahi, E., Aliverdi, N. A., \& Pourhossein, S. Z. Z. (2010). Relationship between social support and mental health, social welfare. Journal of Research and Science, 39, 85-121.

Riebscheger, J., Scheid, C., Luz, C., Mickus, M., Liszewski, C., \& Eaton, M. (2008). How are the experiences and needs of families of individuals with mental illness reflected in medical education guidelines? Academic Psychiatry, 32, 119-126.

Rohini, D. R. N. S. (2012). Management of anxiety in the parents of children with special needs through positive therapy. International Journal of Multidisciplinary Research, 2, 75-91.

Sakakura, K., Ishikawa, J., Okuno, M., Shimada, K., \& Kario, K. (2007). Exaggerated ambulatory blood pressure variability is associated with cognitive dysfunction in the very elderly and quality of life in the younger elderly. American Journal of Hypertension, 20, 720-727.

Saloviita, T., Itallina, M., \& Leinonen, E. (2003). Explaining the parental stress of fathers and mothers caring for a child with intellectual disability: A double ABC X model. Intellectual Disability Research, 47, 300-312

Sheehy, R., \& Horan, J. J. (2004). The effects of stress inoculation training for first year law student. International Journal of Stress Management, 11, 41-55.

Shieve, L. A., Blumberg, S. J., Rice, C., Visser, S. N., \& Boyle, C. (2007). The relationship between autism and parenting stress. Pediatric, 119, 114-121.

Van Leeuwen, M. C., Post, W. M., Van Asbeck, W. F., Vander Woude, H. V., Groot, S., \& Lindeman, E. (2010). Social support and life satisfaction in spinal cord injury during and up to one year after inpatient rehabilitation. Journal of Psychology, 42, 265-271.

Williams J., Steel, C., \& Gregory, B. (2003). Parental anxiety and quality of life in children with epilepsy. Epilepsy \& Behavior, 4, 483-486.

Zaidman-Zait, A. (2007). Parent of disabled children burn-out too: Counseling parents of disabled of children on stress management. Interventional Journal for Advancement of Counseling, 33, 107-118. 